\title{
A PH LEVEL MONITORING IN HYDROPONIC SYSTEM USING ARDUINO
}

\author{
Stevanus Adi Ramli ${ }^{1}$, Rosita Herawati ${ }^{2}$ \\ ${ }^{1,2}$ Program Studi Teknik Informatika Fakultas IImu Komputer, Universitas Katholik \\ Soegijapranata \\ 113020028@student.unika.ac.id, 2rosita@unika.ac.id
}

\begin{abstract}
Hydroponic is one of growing plant method without soil. It uses water as the planting media. As of this writing, hydroponic method is quite popular in Indonesia because it is more hygienic, more results, more environmentally friendly at a lower cost production. Hydroponic life depends on the nutrients in the water. One of the most important of the hydroponic method is $\mathrm{pH}$ level of the water. The standard of $\mathrm{pH}$ level which used to grow a plant is in the range of 5.5 to 6.5 .

To balance the standard of $\mathrm{pH}$ level, liquid for increasing and decreasing $\mathrm{pH}$ level are needed, but it is difficult to measure the $\mathrm{pH}$ level on the standard range while adding the water. Based on this problem, this project will develop an automated device for mixing $\mathrm{pH}$ up and $\mathrm{pH}$ down liquid so the level of $\mathrm{pH}$ will be keep in the desire range using $\mathrm{pH}$ sensor and Arduino microcontroller.
\end{abstract}

Keyword: pH sensor, Arduino, IoT Thingspeak, Hydroponic System.

\section{Pendahuluan}

Hidroponik adalah salah satu media tanam tanpa menggunakan tanah. Media tanam yang digunakan adalah air. Akhir-akhir ini metode tanam hidroponik ini menjadi populer di Indonesia karena higienis, hasil panen lebih banyak, ramah lingkungan dan pembuatannya murah. Tanaman hidroponik tergantung pada nutrisi yang ada pada air. Salaah satu yang paling penting di dalam hidroponik yaitu level $\mathrm{pH}$ dari media tanamnya, karena penyerapan nutrisi melalui media air dan tanaman bisa menyerap nutrisi dengan baik dengan kisaran pH 5,5 sampai 6,5.

Untuk menetralkan standart level $\mathrm{pH}$, cairan $\mathrm{pH}$ up dan $\mathrm{pH}$ down akan dibutuhkan. Tetapi Kegiatan tersebut agak susah ketika menambahkan air, karena air dapat menguap dan harus ditambah agar tanaman tetap hidup. Akan menjadi sangat membatu jika ada sebuah alat yang dapat menjaga level $\mathrm{pH}$ di level yang telah ditentukan dan dapat di monitoring menggunakan android atau komputer, karena tanaman membutuhkan level $\mathrm{pH}$ yang stabil. Berdasar dari permasalahan tersebut, projek ini mengembangkan alat otomatis untuk mencampurkan cairan $\mathrm{pH}$ up dan $\mathrm{pH}$ down dan menjadikan level $\mathrm{pH}$ berada di kisaran yang telah ditentukan menggunakan sensor $\mathrm{pH}$ dan Arduino mikrokontroler. 
Sensor $\mathrm{pH}$ adalah alak elektronik yang dapat mengukur level $\mathrm{pH}$ dalam air. Arduino mengirim data level $\mathrm{pH}$ ke server IoT Thingspeak. Setelah data dikirim ke Thingspeak, pengguna dapat melihat level $\mathrm{pH}$ menggunakan android ataupun perangkat komputer. Ketika level $\mathrm{pH}$ di bawah kisaran yang telah di tentukan, arduino mengalirkan cairan $\mathrm{pH}$ up menggunakan pompa air mikro, dan begitu sebaliknya sehingga level pH mencapai standart yang telah di tentukan.

\section{Landasan Teori}

Jurnal yang digunakan sebagai landasan teori dalam project ini dengan judul, Pengendalian Kadar Keasaman(pH) Pada Sistem Hidroponik Stroberi Menggunakan Kontroler PID Berbasis Arduino Uno, yang di tulis oleh Ika Kustanti, M.Aziz Muslim, Erni Yudaningtyas. Topik yang di tulis tentang mengontrol level $\mathrm{pH}$ untuk tanaman sistem hidroponik tanaman stroberi. Metode yang digunakan adalah PID kontrol. PID adalah pengulangan dari mekanisme timbal balik, jadi tiap sensor yang digunakan akan memberikan timbal balik dan mengkalkulasi berapa banyak cairan yang akan dialirkan.

Ada pula jurnal berjudul : Implementasi Fuzzy Logic Control Untuk Mengatur pH Nutrisi pada Sistem Hidroponik Nutrient Film Technique(NFT), disusun oleh , Dian Pancawati dan Andik Yulianto dari Universitas Internasional Batam, adalah implementasi Fuzzy Logic Control untuk mengukur nutrisi di dalam sistem hidroponik. Proyek tersebut meneliti perbedaan antara penanaman dengan media hidroponik tanpa menggunakan sistem kontrol $\mathrm{pH}$, dengan media hidroponik yang menggunakan sistem kontrol $\mathrm{pH}$.

\section{Metodologi Penelitian}

Untuk membuat sistem hidroponik dengan arduino, langkah-langkah dan peralatan yang dibutuhkan yaitu :

1. Membuat Seperangkat Media Hidroponik

Untuk membuat perangkat media hidroponik, dibutuhkan bahan-bahan antara lain, pvc, talang, penutup talang, pompa air untuk aquarium, penampung air. Pertama yang dilakukan adalah membuat rak untuk menempatkan tanaman, kemudian membuat irigasi dari talang yang di bentuk sesuai keinginan.

2. Membuat Sistem Otomatisasi Penstabil pH Untuk Perangkat Media Hidroponik

Untuk mengontrol level $\mathrm{pH}$ pada media hidroponik dibutuhkan beberapa komponen yaitu, Modul ESP8266 D1, pH sensor , dua buah pompa air kecil 36vDC dan Module Motor Driver L298N Dual H-Bridge untuk mengontrol dua buah pompa air kecil. 
3. Pengumpulan Data

Data yang dikumpulkan di proyek ini berisi data yang didapatkan oleh sensor pH yang terinstal di modul hidroponik. Dan kemudian di kirim ke server IoT Thingspeak.

4. Pengetesan Modul

Tujuan dari pengetesan modul adalah untuk mengetahui kekurangan dari modul yang telah dibuat dan memperkecil kekurangan tersebut. Hasil dan Pembahasan

Komponen-komponen yang digunakan dalam proyek ini adalah,

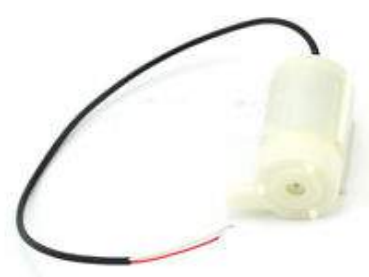

Gambar 1: Pompa Air Mikro

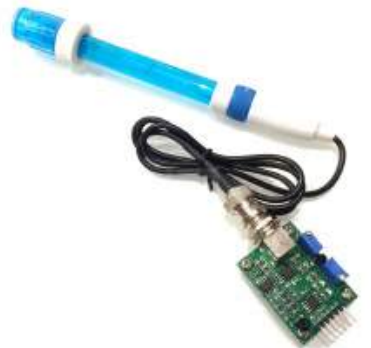

Gambar 2: Sensor $p H$ dan Modul Sensor $\mathrm{pH}$

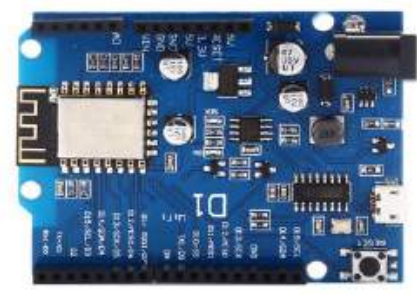

Gambar 3: Modul Arduino ESP8266 D1
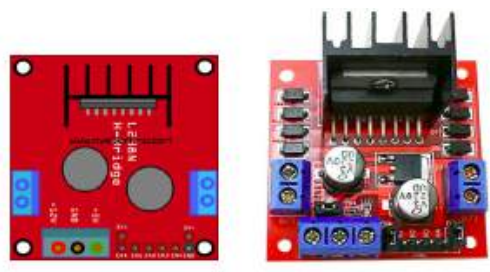

Gambar 4: Driver Motor L298N Dual H-Bridge

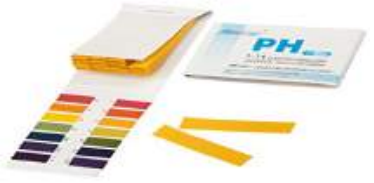

Gambar 5: Kertas Lakmus

Penjelasan gambar komponen ,

1. Gambar 1 adalah gambar dari modul arduino yang di gunakan dalam proyek ini.

2. Berikutnya ada Pompa Air Mikro untuk mengalirkan cairan $\mathrm{pH}$ up dan $\mathrm{pH}$ down.

3. Setelah itu ada $\mathrm{pH}$ sensor dan modulnya untuk mengukur tingkat $\mathrm{pH}$ dalam air

4. Ada pula Driver Motor L298N untuk mengendalikan kecepatan dan memberi inputan kepada Pompa Air Mikro.

5. Berikutnya adalah Kertas Lakmus untuk pengetesan apakah pengukuran dari sensor $\mathrm{pH}$ itu benar 


\section{Water Pump Speed}

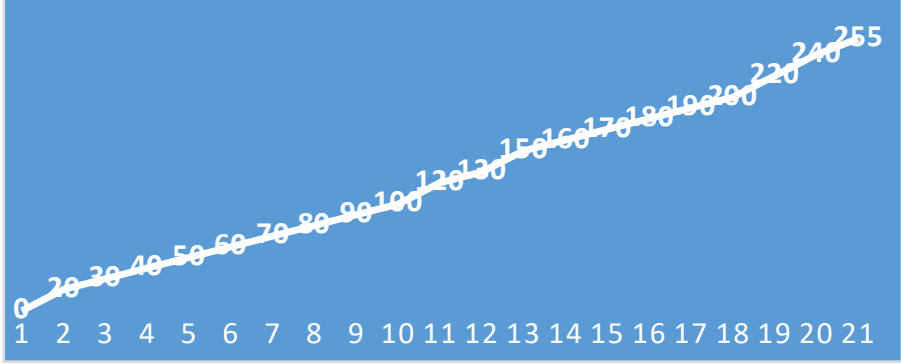

Gambar 6: Diagram Garis Kecepatan Pompa Air

Gambar diagram garis di atas merupakan rekap dari kecepatan pompa air.

\begin{tabular}{|c|c|}
\hline Speed & Drain Liquid \\
\hline & $0 \mid 0 \mathrm{ml}$ \\
\hline & $2010 \mathrm{ml}$ \\
\hline & $30 \mid 0 \mathrm{ml}$ \\
\hline & $40 \mid 0 \mathrm{ml}$ \\
\hline & $50 \mid 0.5 \mathrm{ml}$ \\
\hline & $6410 \mathrm{ml}$ \\
\hline & $70 \mid 12 \mathrm{ml}$ \\
\hline & $8015 \mathrm{ml}$ \\
\hline & $9016 \mathrm{ml}$ \\
\hline & $100 \mid 18 \mathrm{ml}$ \\
\hline & $12020 \mathrm{ml}$ \\
\hline & \begin{tabular}{l|l|l|}
$30 \mathrm{ml}$ \\
\end{tabular} \\
\hline & \begin{tabular}{l|l|}
150 & $27 \mathrm{ml}$ \\
\end{tabular} \\
\hline & $160 \mid 30 \mathrm{ml}$ \\
\hline & $170 \mid 32 \mathrm{ml}$ \\
\hline & $180 \mid 34 \mathrm{ml}$ \\
\hline & $190 \mid 35 \mathrm{ml}$ \\
\hline & $20040 \mathrm{ml}$ \\
\hline & $220 \mid 42 \mathrm{ml}$ \\
\hline & \begin{tabular}{ll|l|}
240 & $45 \mathrm{ml}$ \\
\end{tabular} \\
\hline & 1 1: Tabe \\
\hline
\end{tabular}

Air

Tabel di atas merupakan tabel pengetesan cairan yang dapat dialirkan karena tiap kecepatan memiliki potensi mengalirkan cairan yang berbeda. Pompa Air Mikro perlu di atur karena cairan yang digunakan dalam proyek ini sangat kuat, jika penyemprotan tidak diatur akan terjadi kekacauan ketika menstabilkan tingkat $\mathrm{pH}$. 


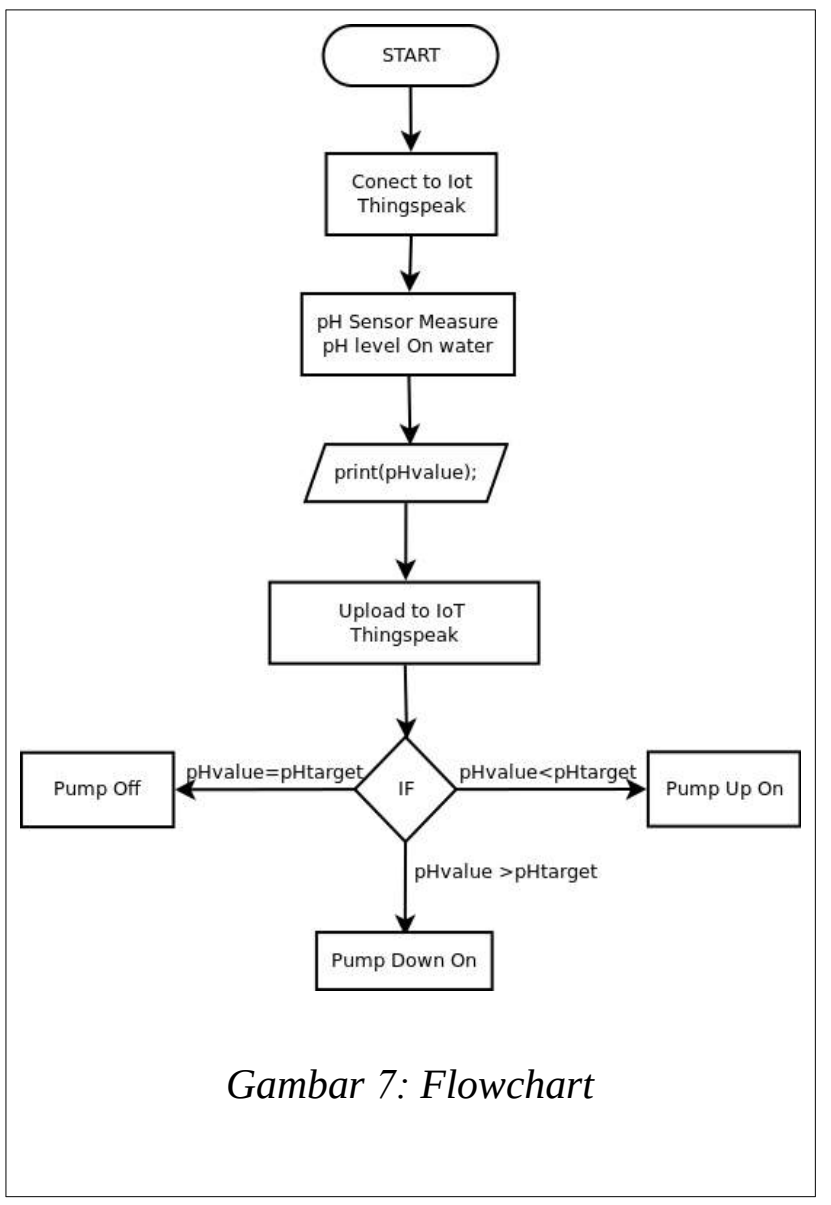

Flow chart diatas merupakan penjelasan alur secara mendetail dari proyek yang akan dirancang, untuk mempermudah dalam perancangan alat.

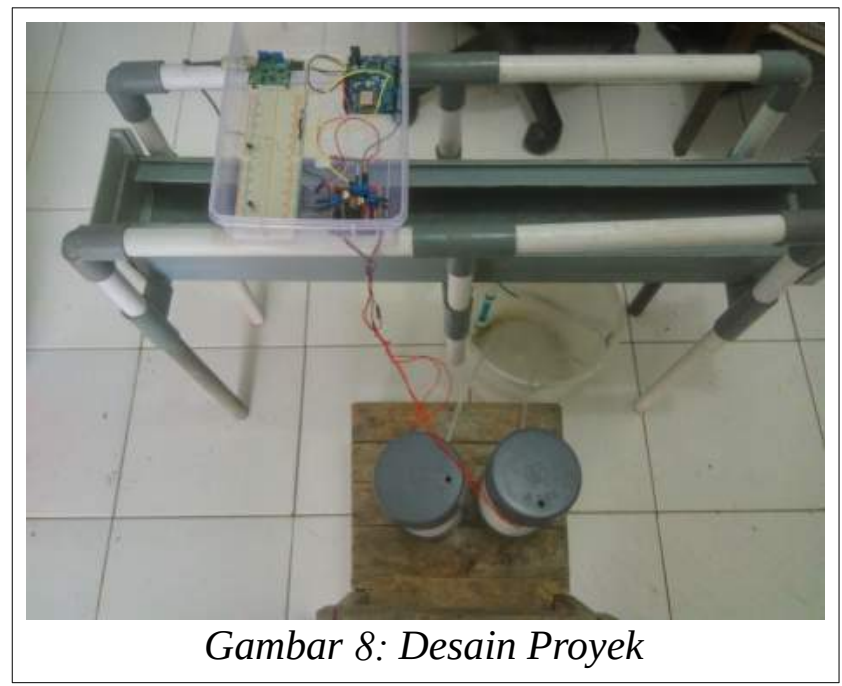

Gambar di atas merupakan desain final dari proyek. Pompa air mikro di desain sedemikian rupa, agar dapat mengalirkan cairan dari tempat penampungan cairan $\mathrm{pH}$. 


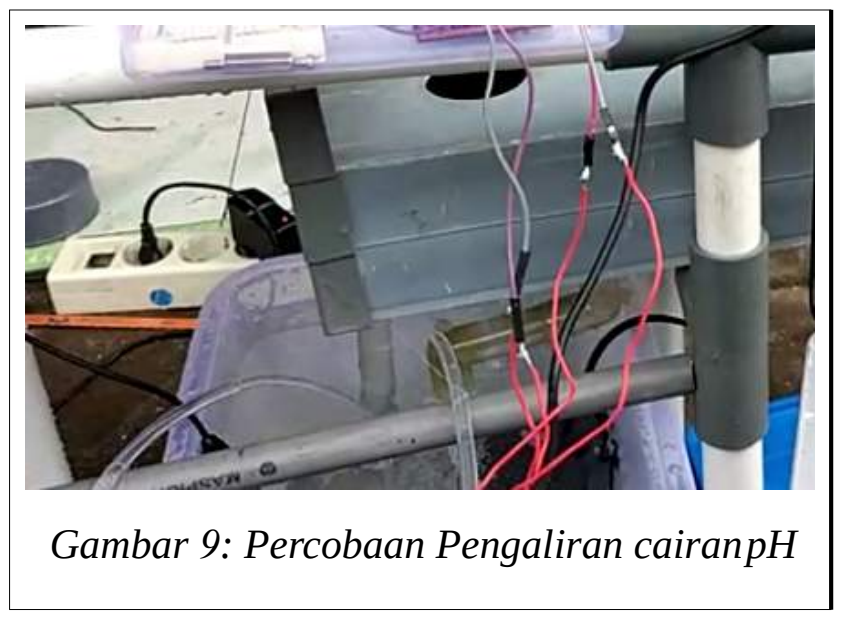

Gambar di atas merupakan percobaan dilakukan menggunakan air yang memiliki kisaran $\mathrm{pH}$ antara 5 sampai6. Volume air yang digunakan kisaran antara 5 sampai 7 liter. Gambar di atas terlihatpompa di dalam tangki berisi cairan $\mathrm{KOH}(\mathrm{Kalium}$ Hidroksida) sedang bekerjamengalirkan cairan.

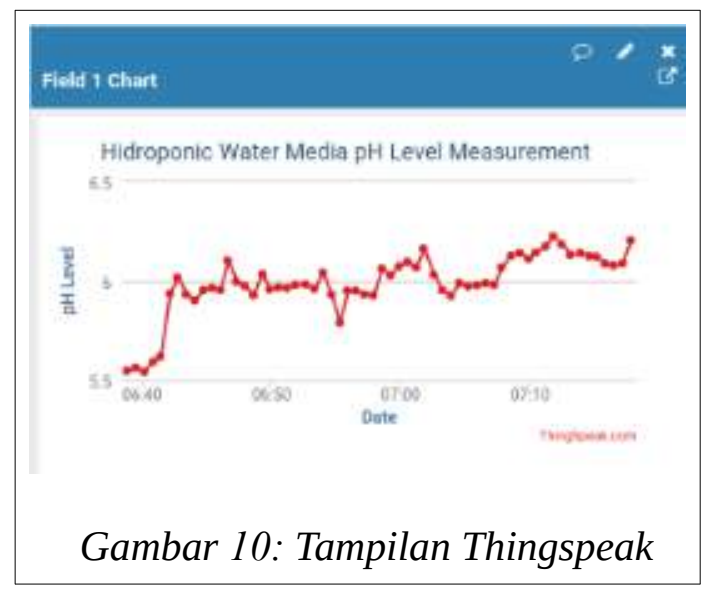

Gambar diatas merupakan tampilan monitoring pengukuran sensor $\mathrm{pH}$ dari situs Thingspeak. Dapat di lihat bahwa terjadi kenaikan $\mathrm{pH}$ merupakan efek dari pengontrolan tingkat $\mathrm{pH}$ dari 5.5 naik menjadi 6 karena standart $\mathrm{pH}$ yang telah ditentukan adalah 6. Dapat di analisa pula pengukuran dari sensor pH kurang stabil mengalami penaikan dan penurunan ketika melakukan pengukuran karena media tanam hidroponik airnya berarus, efek dari pencampuran nutrisi menggunakan pompa air. 


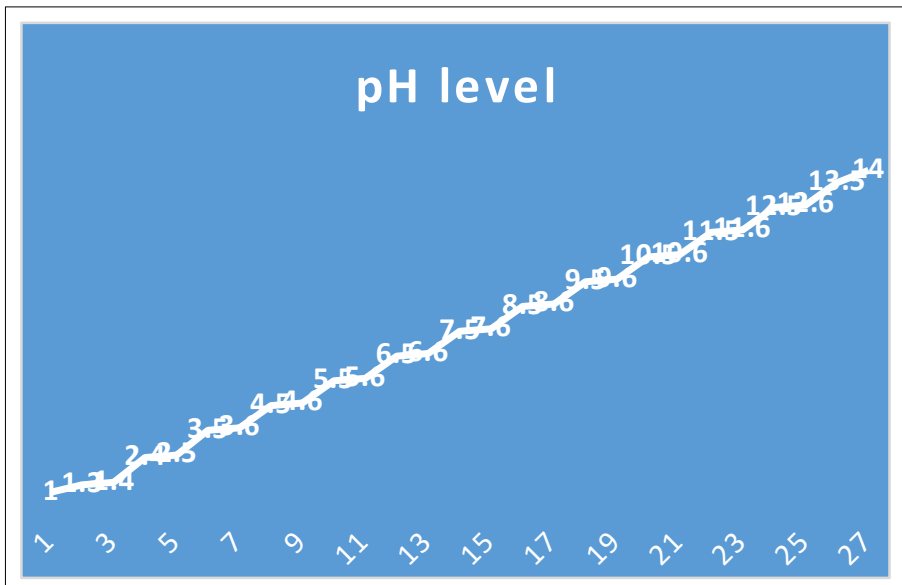

Gambar 11: Diagram Pengukuran pH sensor

Diagram garis diatas merupakan pengetesan pengukuran $\mathrm{pH}$ sensor yang mana airnya dinaikan tingkat $\mathrm{pH}$ nya menggunakan cairan Asam Sulfat dan Kalium Hidroksida.

Tabel 2:Tabel Perbandingan

\begin{tabular}{|c|c|}
\hline PH sensor & Kertas Lakmus \\
\hline $\mathbf{1 - 1 . 3}$ & $\mathbf{1}$ \\
\hline $1.4-2.4$ & $\mathbf{2}$ \\
\hline $2.5-3.5$ & $\mathbf{4}$ \\
\hline $3,6-4,5$ & $\mathbf{5}$ \\
\hline $4,6-5,5$ & $\mathbf{6}$ \\
\hline $5,6-6,5$ & $\mathbf{7}$ \\
\hline $6,6-7,5$ & $\mathbf{8}$ \\
\hline $7,6-8,5$ & $\mathbf{9}$ \\
\hline $8.6-9.5$ & $\mathbf{1 0}$ \\
\hline $9,6-10.5$ & $\mathbf{1 1}$ \\
\hline $10,6-11,5$ & $\mathbf{1 2}$ \\
\hline $11,6-12,5$ & $\mathbf{1 3}$ \\
\hline $12,6-13.5$ & $\mathbf{1 4}$ \\
\hline 14 & \\
\hline
\end{tabular}

Tabel di atas adalah hasil dari perbandingan level $\mathrm{pH}$ dari pengukuran sensor $\mathrm{pH}$ dengan pengukuran menggunakan Kertas Lakmus. 


\section{Kesimpulan}

Proyek ini mengendalikan tingkat $\mathrm{pH}$ air di media tanam hidroponik, yang bisa diamati oleh pengguna dari komputer mereka (website) atau smartphone (aplikasi android). Perangkat ini melakukan pengendalian kadar $\mathrm{pH}$ pada air, perangkat ini juga bisa dipantau menggunakan server Thesepeak IoT yang bisa diakses menggunakan smartphone atau komputer. Pengukuran tingkat $\mathrm{pH}$ pada air dengan sensor $\mathrm{pH}$ diupload ke Thingspeak. Jadi orang bisa melihat tingkat $\mathrm{pH}$ yang ditetapkan pada target $\mathrm{pH}$.

Tingkat PH dikontrol oleh dua pompa air (Pump Up \& Down), bila tingkat $\mathrm{pH}$ lebih dari target $\mathrm{pH}$, Pompa Turunkan cairan dari tangki bawah yang mengandung H2SO4 (Asam Sulfat), dan bila tingkat $\mathrm{pH}$ kurang dari target $\mathrm{pH}$, maka Pump Up mengalirkan cairan dari tangki ke atas yang mengandung $\mathrm{KOH}$ (Kalium Hidroksida). Setelah mengendalikan $\mathrm{pH}, \mathrm{pH}$ sensor mengukur tingkat $\mathrm{pH}$ pada air bila tingkat $\mathrm{pH}$ masih belum sesuai dengan target $\mathrm{pH}$, maka Pump Up \& Down akan mengalirkan cairan sampai $\mathrm{pH}$ mencapai target.

Saat membuat perangkat ini, ada masalah saat perangkat mengukur tingkat $\mathrm{pH}$ dan pada saat bersamaan pompa air naik dan turun menyala, pengukuran tingkat $\mathrm{pH}$ menjadi tidak stabil karena sensor $\mathrm{pH}$ sensitif dengan sinyal listrik. Untuk proyek pengembangan selanjutnya dianjurkan untuk menggunakan dua arduino yang terhubung dengan server IoT. Arduino pertama adalah untuk mengukur tingkat $\mathrm{pH}$ dan menulis data ke server IoT. Sedangkan arduino kedua dibaca data dari server IoT untuk mendapatkan nilai yang dibutuhkan untuk mengendalikan pompa air, sehingga pengukuran $\mathrm{pH}$ akan lebih akurat dan stabil.

\section{Daftar Pustaka}

[1] Pancawati, Dian \& Yulianto, Andik, Program Studi Teknik Elektro, Fakultas Teknologi Industri, Universitas International Batam(2016): Implementasi Fuzzy Logic Controller Untuk Mengatur PH Nutrisi Pada Sistem Hidroponik Nutrient Film Technique(NFT). National Journal Of Electrical Engineering ISSN:2302-2949Vol:5,No.2,278-289.

[2] Kustanti, Ika \& M. Aziz Muslim, Erni Yudaningtyas (2014): Pengendalian Kadar Keasaman $(\mathrm{pH})$ Pada Sistem Hidroponik Stroberi Menggunakan Kontroler PID Berbasis Arduino Uno, Jurnal Mahasiswa TEUB, Vol :2, No.1, p-ISSN: 23022949, e-ISSN: 2407-7267. 